\title{
Análise do conforto térmico em modelos reduzidos de galpões agrícola
}

\author{
Analysis of thermal comfort in reduced models of agricultural sheds \\ Irajá Jantsch de Souza ${ }^{1}$, Zanandra Boff de Oliveira $^{2}$, Ezequiel Saretta ${ }^{3}$, Larrissa Ribeiro Rodrigues ${ }^{4}$, \\ Clarissa Moraes da Silva ${ }^{5}$ e Tiago Tondolo Link ${ }^{6}$ \\ 1,2,3,4,5,6 Universidade Federal de Santa Maria, Cachoeira do Sul, Brasil \\ Iraja_14@yahoo.com.br; Zanandraboff@gmail.com; Ezequiel.saretta@ufsm.br; Larrissarodriguesmtm@gmail.com \\ Clarissamoraes37@outlook.com; Tiagotondololink@hotmail.com
}

\section{Resumo}

O presente trabalho teve como objetivo avaliar o conforto térmico por meio do Índice de Temperatura e Umidade (ITU) no interior de modelo de galpões avícolas em escala reduzida, utilizando diferentes estratégias de cobertura. O experimento foi realizado na Universidade Federal de Santa Maria campus Cachoeira do Sul. As coberturas utilizadas foram: fibrocimento (testemunha), fibrocimento + pintura em branco + manta térmica, fibrocimento + pintura em branco. A leitura da temperatura e da umidade relativa do ar foram realizadas no interior de cada modelo e na área externa, com sensores DTH 22 controlados por Arduino, divido em quatro periodo do verão 2017/2018. Em comparação ao ambiente externo, as diferentes coberturas promoveram redução média do ITU de 84 para 76. Observou-se diferenças estatísticas significativas entre as diferentes coberturas, em que o ITU médio do periodo de 77,31 observado na testemunha foi reduzido para 74,90 nas coberturas com pintura em branco. Baseado nas condições em que o estudo foi conduzido recomenda-se a cobertura de fibrocimento + pintura em branco para a melhoria do conforto térmico no interior dos galpões avícolas.

Palavras-chave: Conforto térmico; Cobertura; Frango de corte; Arduino; Galpões avícolas

\section{Abstract}

The present work had the objective of evaluating the thermal comfort by means of the Temperature and Humidity Index (ITU) inside a model of small scale poultry houses using different hedging strategies. The experiment was carried out at the Federal University of Santa Maria Cachoeira do Sul. The coverings used were: fiber cement (control), fiber cement + white paint + thermal blanket, fiber cement + white paint. The temperature and relative air humidity reading were performed inside each model and in the external area, with DTH 22 sensors controlled by Arduino, divided in four periods of summer 2017/2018. Compared to the external environment, the different coverages promoted a mean reduction of ITU from 84 to 76 . Significant statistical differences between the different coverage were observed, in which the average ITU of the period of 77.31 observed in the control was reduced to 74.90 on the covers with white paint. Based on the conditions under which the study was conducted, it is recommended to cover asbestos cement + white paint to improve thermal comfort inside poultry houses.

Keywords: Thermal comfort; Roof; Chicken cut; Arduino; Poultry houses 


\section{Introdução}

A carne de frango é consumida em quase todo mundo, isto porque, além da sua qualidade e baixo custo, muitas culturas não permitem o consumo de outras fontes de proteína animal. Esse crescimento exigiu dos produtores uma maior eficiência na criação de frangos, aumentando os cuidados relacionados à alimentação, manejo, genética e ambiência Cardoso (2014). A avicultura de postura, também é um segmento importante na produção de alimento humano, ocupando posição de destaque na economia brasileira ANDRADE (2017). A produção de ovos de galinhas poedeiras totalizou 39,1 bilhões de unidades produzidas no ano de 2016 IBGE (2017).

No município de Cachoeira do Sul, existe um aumento crescente na produção de aves e de ovos (Ibge 2006; 2015). As perspectivas são de que ocorra um acréscimo dessa atividade, haja vista, a mudança na cadeia produtiva de bovinos de corte, pois houve uma migração de áreas de pastagem para áreas de lavouras (cultura da soja), além da necessidade de diversificação das atividades na propriedade rural, para a garantia de renda e sustentabilidade da mesma. Neste sentido, a criação de aves de corte e de postura, pode ser uma atividade cada vez mais explorada no município.

Em climas tropicais e subtropicais, como é o caso de Cachoeira do Sul, os elevados valores de temperatura e umidade relativa do ar destacam-se entre os principais fatores que interferem negativamente na criação de aves CASTRO et al. (2009). Para Casa e Ravelo (2003), quando a temperatura e a umidade estão fora do ideal, levam o animal a ficar fora da sua zona de conforto, causando estresse e provocando impactos negativos na produção, no comportamento na sanidade e no bem-estar da criação.

De acordo com Camerini et al. (2009), em países tropicais e subtropicais, o maior ganho térmico em edificações ocorre principalmente através da cobertura por ser a superfície mais exposta à radiação solar. Machado et al. (2012) afirmaram que, a alta incidência de radiação solar sobre a cobertura das instalações avícolas é um dos principais causadores do estresse térmico nos aviários. $\mathrm{O}$ acréscimo na temperatura interna é percebido, principalmente, nas instalações que possuem telhas aparentes, ou seja, quando a mesma não possui forro (ou laje) para separar o espaço do restante da edificação. Sabe-se que, com o uso de telhas de cimento amianto, o desconforto térmico é maior do que nas telhas de argila, pois uma parte da energia que incide na superfície das telhas de barro é gasta no processo de evaporação da água, absorvida durante a noite devido à condensação do vapor de água existente no ar. Assim, o fluxo de calor que atinge o interior da instalação é menor se a instalação for comparada com a que tiver telhas de cimento amianto (Camerini et al. 2009; Nããs et al. 2004).De acordo com Moura (2001), para melhorar a produção avícola intensiva em países como o Brasil, é necessário aperfeiçoar os abrigos e equacionar o manejo para superar os efeitos prejudiciais provenientes de alguns fatores ambientais críticos, que refletirão na produtividade do sistema.

O desenvolvimento de pesquisas sobre instalações para avicultura em escala natural apresenta custo elevado Sevegnani et al. (1994), além de demandar um longo tempo para o desenvolvimento e adaptação dos projetos. Para que estudos sejam economicamente viáveis, utilizam-se normalmente modelos físicos de galpões avícolas construídos em escala reduzida Santos et al. (2005). Alguns estudos, com essa formatação foram desenvolvidos no Brasil, como é o caso do trabalho realizado por Silva et al. (2015), Cardoso (2014), Curto et al. (2007), entre outros. O ambiente térmico no interior de modelos construídos em escala pode ser avaliado por vários índices. Dentre eles, pode-se destacar o Índice de Temperatura e Umidade (ITU), calculado a partir dos efeitos combinados da temperatura do ar e umidade relativa conforme Buffington (1982).

Assim, justificam-se estudos que avaliem técnicas e materiais de construções que propiciem às aves condições ambientais favoráveis para que estas possam expressar todo o seu potencial genético, buscando ao máximo a eficiência do sistema, para que alterações no ambiente sejam minimizadas, reduzindo os custos de produção. Objetivo do trabalho é avaliar 
o ambiente térmico por meio do ITU no interior de modelos de galpões avícolas em escala reduzida, utilizando diferentes estratégias de cobertura.

\section{Material e métodos}

A pesquisa foi realizada na Universidade Federal de Santa Maria Campus de Cachoeira do Sul (30 $02^{\prime} 21^{\prime \prime} \mathrm{S}$ e 52 53' 38" W, altitude 68 m), na região da Depressão Central do Estado do Rio Grande do Sul. O clima da região é classificado por Köppen como subtropical úmido, predominante na região Sul.

As estratégias de cobertura avaliadas foram: (i) telha de fibrocimento sem pintura (testemunha); (ii) telha de fibrocimento com pintura branca e manta térmica; (iii) telha de fibrocimento com pintura branca. Os modelos (em escala reduzida) foram construídos a partir de medidas reais de galpões utilizados na avicultura de corte. Galpões comerciais apresentam, de maneira geral, largura de $12 \mathrm{~m}$, comprimento de $120 \mathrm{~m}$, pé-direito de 3,5 m, espaçamento entre tesouras de 5 $\mathrm{m}$, beiral de $1,0 \mathrm{~m}$ e muretas laterais de $0,15 \mathrm{~m}$. Com o processo de redução para a escala 1:10 as medidas dos modelos utilizadas serão: largura de 1,2 m, comprimento de $1,5 \mathrm{~m}$ - dever-se-ia utilizar $12 \mathrm{~m}$, entretanto será utilizado $1,5 \mathrm{~m}$ (equivalente a 3 módulos de 5m) conforme trabalhos de Santos et al. (2005) e Ferreira júnior et al. (2009) - pé-direito de 0,35 $\mathrm{m}$, beiral de $0,10 \mathrm{~m}$ e muretas de $1,5 \mathrm{~cm}$. A inclinação do telhado será de $15 \%$, conforme ilustra a figura 1 .

Figura 1 - Fachada frontal do galpão aviário em escala reduzida (medidas expressas em $\mathrm{cm}$ )

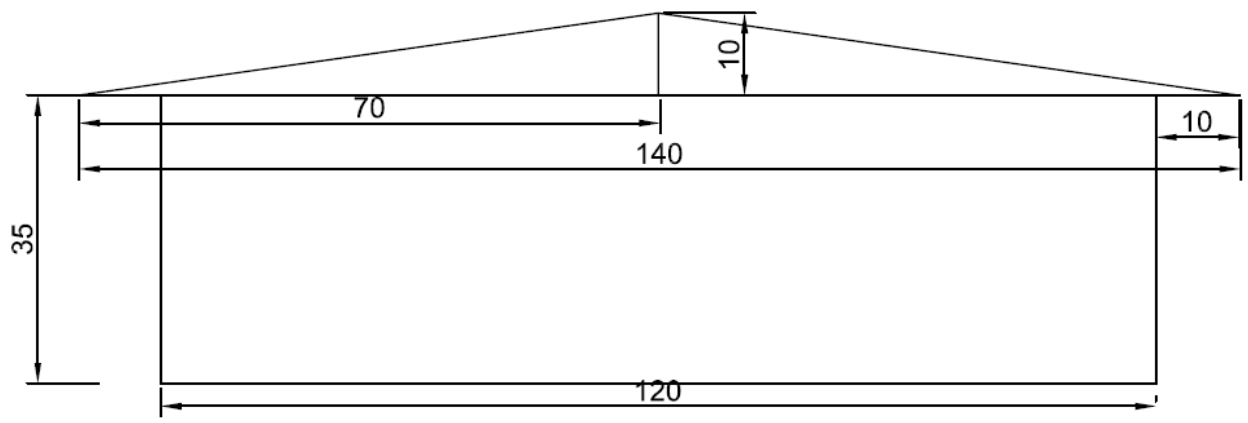

Os modelos foram instalados em terreno plano, livres de sombreamento, orientados no sentido leste oeste e distanciados dois metros um do outro, segundo recomendação de Fonseca et al. (2011), figura 2.

Figura 2 - Galpões com diferentes tipos de telhado e instalação interna do sensor DTH 22

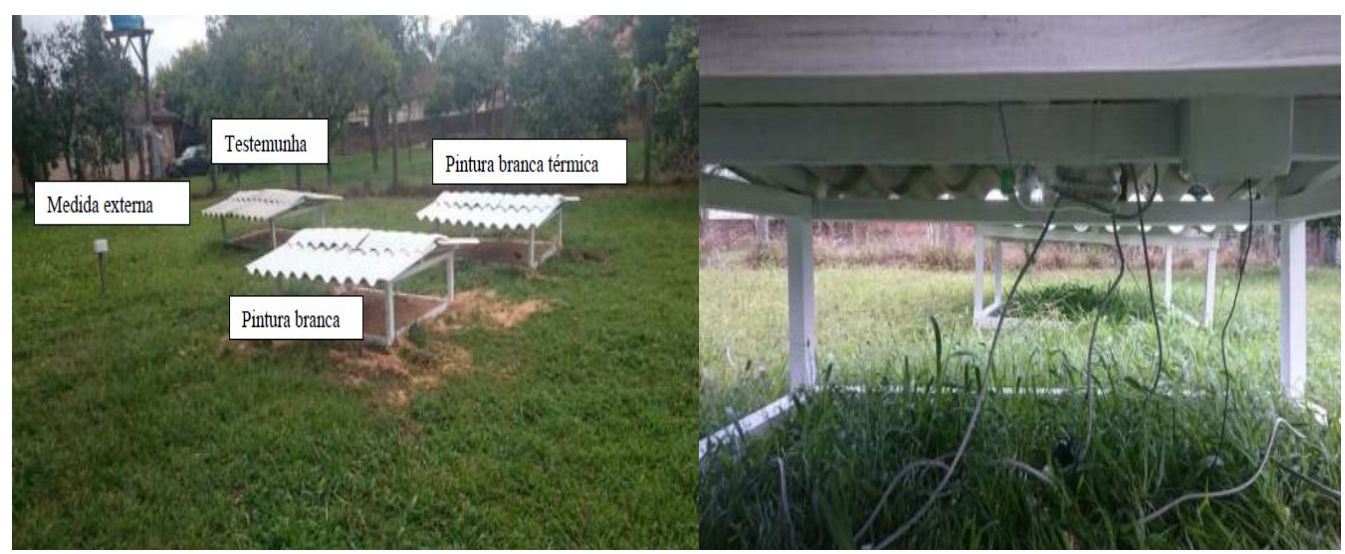


A análise do conforto térmico no interior de cada galpão avícola em escala reduzida, foi realizada em quatro períodos: $1^{\circ}$ - 30/11/2017 a 6/12/2017; $2^{\circ}-31 / 01 / 2018$ a 06/02/2018; $3^{\circ}-07 / 02 / 2018$ a $14 / 02 / 2018$ e o $4^{\circ}-15 / 02 / 2018$ a $22 / 02 / 2018$. Para isso, foram utilizados sensores de umidade e temperatura DHT 22, que realiza leituras de temperaturas entre $-40 \mathrm{a}+80^{\circ} \mathrm{C}$ e umidade relativa entre 0 a 100\%, controlado por Arduíno. As leituras foram realizadas às $12 \mathrm{~h} 00$. De posse desses dados, o ITU foi calculado a partir da equação proposta por Bunffington (1997):$$
\mathrm{ITU}=\frac{0,8 T b s+U R(T b s-14,3)}{46,3+100}
$$

(1)

Onde:

ITU = índice de temperatura e umidade, adimensional;

Tbs = temperatura de bulbo seco, ${ }^{\circ} \mathrm{C}$;

$\mathrm{UR}=$ umidade relativa do ar, \%.

Os valores obtidos de ITU, assim com os valores de temperatura e umidade relativa do ar, foram comprados com as condições ideais de conforto térmico para aves, em função da sua idade em semanas de vida (Tabela 1).

Tabela 1- Valores de conforto de temperatura, umidade relativa do ar e do índice de temperatura e umidade (ITU), em função da idade das aves

\begin{tabular}{l|l|l|l}
\hline Idade (semanas) & Temperatura $\left({ }^{\circ} \mathbf{C}\right)$ & Umidade relativa (\%) & ITU \\
\hline $\mathbf{1}$ & $32-35$ & $60-70$ & $72,4-80$ \\
\hline $\mathbf{2}$ & $29-32$ & $60-70$ & $68,4-76$ \\
\hline $\mathbf{3}$ & $26-29$ & $60-70$ & $64,8-72$ \\
\hline $\mathbf{4}$ & $23-26$ & $60-70$ & $60,5-68$ \\
\hline $\mathbf{5}$ & $20-23$ & $60-70$ & $56,6-64$ \\
\hline $\mathbf{6}$ & 20 & $60-70$ & $56,6-60$ \\
\hline
\end{tabular}

Fonte: Abreu; Abreu (2002); Silva (2007)

Os dados ITU foram submetidos análise de variância empregando-se o teste "F". As médias foram comparadas pelo teste de Tukey a 0,05 de probabilidade. Para realização das análises estatísticas foi utilizado o software estatístico SISVAR. Para isso, considerou-se o delineamento experimental de blocos ao acaso com três tratamentos (estratégias de cobertura) e sete repetições (número de dias de avaliação de cada período).

\section{Resultados e discussão}

Na Figura 3 apresenta-se os resultados de temperatura e umidade relativa do ar observados no ambiente externo aos modelos reduzidos.

Os valores de temperatura e umidade relativa de ar do ambiente externo variaram entre 22,3 a $43,3{ }^{\circ} \mathrm{C}$ e 39,6 a $90 \%$, respectivamente. Com exceção aos dias chuvosos, a umidade relativa do ar esteve abaixo dos valores considerados como ideais conforme apresentado na Tabela 1. A temperatura do ar, em uma grande parte do período de avaliação, foi de conforto térmico para animais nas 3 primeiras semanas de vida. Já, para animais a partir da $3^{\mathrm{a}}$ semana de vida, a temperatura do ar foi superior à de conforto térmico na maior parte do período, indicando estresse calórico (Abreu; Abreu, 2002; Silva, 2007). 
Figura 3 - Temperatura e umidade relativa do ar observadas em ambiente externo aos modelos de galpões avícolas em escala reduzida

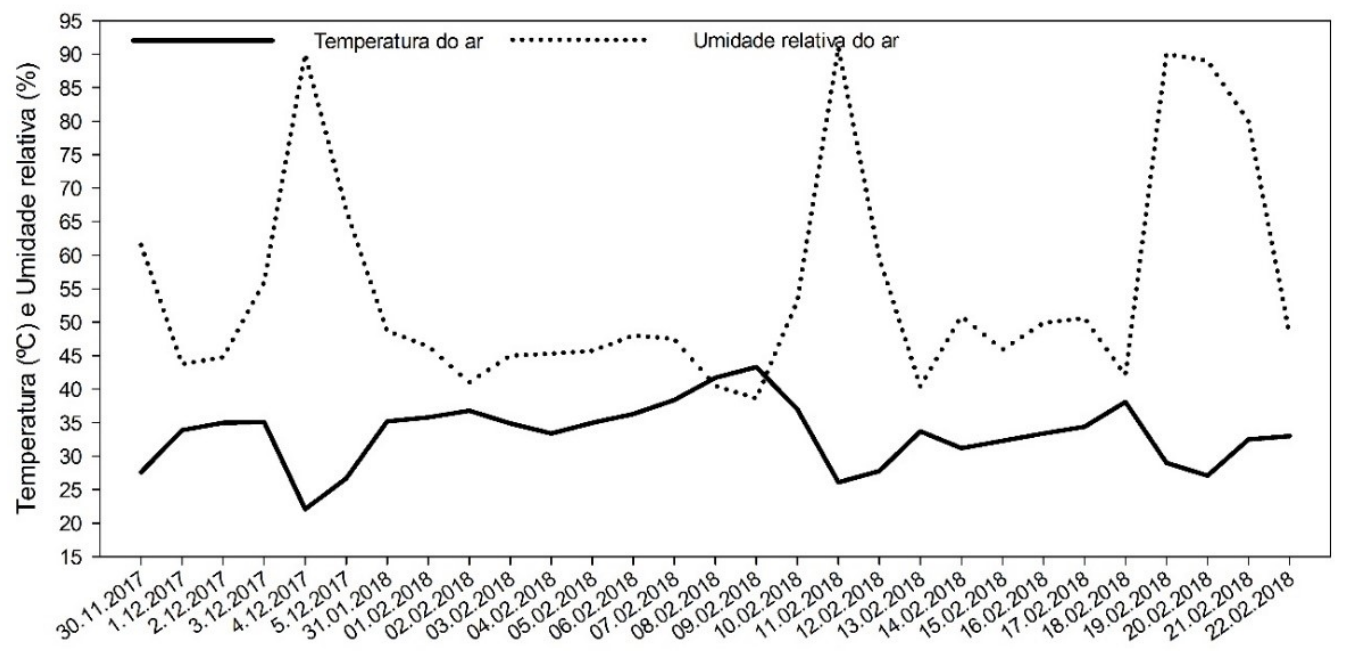

A suscetibilidade das aves ao estresse calórico aumenta à medida que a umidade relativa e a temperatura do ar ultrapassam a zona de conforto térmico, dificultando assim a dissipação de calor, incrementando consequentemente a temperatura corporal da ave, com efeito negativo sobre o desempenho Borges et al (2003). Assim, a integração dessas duas variáveis pode ser observada por meio do ITU na Figura 4.

Figura 4 - Índice de Temperatura e Umidade observado em ambiente externo e no interior dos modelos de galpões avícolas em escala reduzida

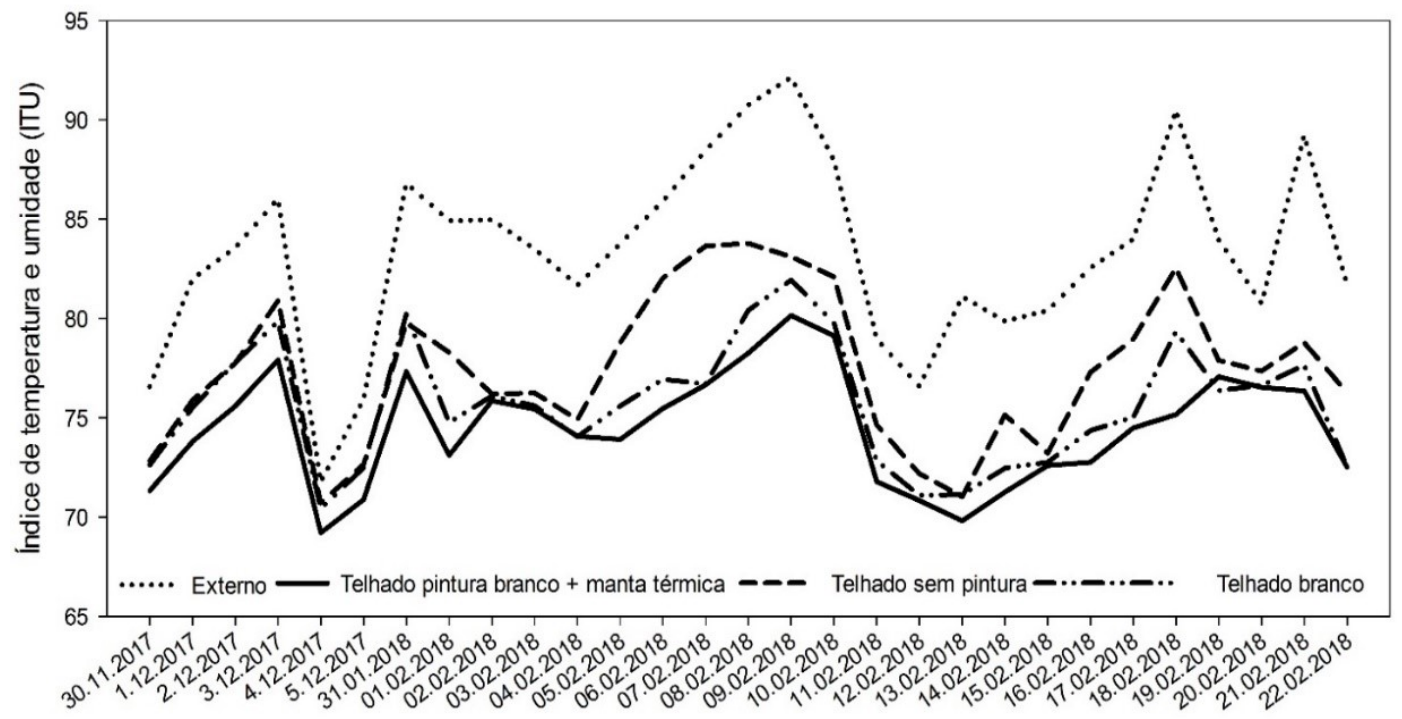

Em comparação ao ambiente externo, as diferentes coberturas promoveram redução média do ITU de 84 para 76. Assim, observou-se diferenças estatísticas significativas entre as coberturas, conforme ilustra a Tabela 2. 
Tabela 2 - Indicadores estatísticos para a comparação do ITU nas diferentes estratégias de cobertura utilizadas nos modelos avícolas em escala reduzida

\begin{tabular}{c|c|c|c|c}
\hline Indicador estatístico & Período de avaliação 1 & Período de avaliação 2 & $\begin{array}{c}\text { Período de } \\
\text { avaliação 3 }\end{array}$ & $\begin{array}{c}\text { Período de } \\
\text { avaliação 4 }\end{array}$ \\
\hline $\mathrm{Pr}>\mathrm{Fc}$ & $0,000^{*}$ & $0,000^{*}$ & $0,000^{*}$ & $0,000^{*}$ \\
\hline $\mathrm{CV}(\%)$ & 1,46 & 1,50 & 2,30 & 2,17 \\
\hline $\mathrm{DMS}$ & 1,63 & 1,77 & 2,11 & 2,09 \\
\hline
\end{tabular}

*Significativo pelo teste $\mathrm{F}$ em nível de $5 \%$ de probabilidade de erro

Na Tabela 3 e Figura 4 observa-se que os maiores valores de ITU (ITU $>75$ ) foram observados nos períodos de avaliação 2 e 3 (final de janeiro até meados de fevereiro) seguindo a mesma dinâmica da temperatura do ar (Figura 1). Nessas condições, é inviável a criação de frangos de corte da $2^{\circ}$ a $6^{\circ}$ semana de vida, conforme os valores de ITU de referência propostos por Abreu e Abreu (2011); Silva (2007), a menos que sejam adotadas alternativas para modificação ambiental.

O ITU do modelo de galpão avícola em escala reduzida com telhado sem pintura foi reduzido em média (4 períodos) de 77,31 para 74,90 com a utilização da pintura branca na cobertura de fibrocimento.

Tabela 3 - Valores médios de ITU para as diferentes estratégias de cobertura utilizadas nos galpões avícolas em escala reduzidas nos quatro períodos de avaliação.

\begin{tabular}{|c|c|c|c|c|}
\hline Tratamento & $\begin{array}{l}\text { Período de } \\
\text { avaliação } 1\end{array}$ & Período de avaliação 2 & $\begin{array}{c}\text { Período de avaliação } \\
\mathbf{3}\end{array}$ & Período de avaliação 4 \\
\hline Telhado branco + manta & $73,12 \mathrm{a}$ & $75,16 \mathrm{a}$ & $75,23 \mathrm{a}$ & $74,30 \mathrm{a}$ \\
\hline Telhado branco & $74,78 \mathrm{~b}$ & $76,19 \mathrm{a}$ & $76,23 \mathrm{a}$ & $75,23 \mathrm{a}$ \\
\hline Telhado sem pintura & $75,12 \mathrm{~b}$ & $78,03 \mathrm{~b}$ & $78,63 \mathrm{~b}$ & $77,49 \mathrm{~b}$ \\
\hline Ambiente externo & $80,38 \mathrm{c}$ & $84,19 \mathrm{c}$ & $85,14 \mathrm{c}$ & $83,66 \mathrm{c}$ \\
\hline
\end{tabular}

Médias seguidas pelas mesmas letras nas colunas não diferem entre si pelo teste de Tukey.

Com exceção ao $1^{\circ}$ período de avalição, em que se observou diferenças estatísticas significativas entre os tratamentos cobertura branco (ITU $=74,78)$ e cobertura branco + manta $(73,12)$, para os demais períodos de avaliação estes não defeririam estatisticamente. Indicando assim, que a estratégia de pintura do telhado em branco, que se apresenta como uma alternativa de baixo custo, pode contribuir para a melhoria do conforto térmico em galões avícolas.

Os valores de ITU (ITU $>73<76)$ obtidos no interior dos modelos de galpões avícolas em escala reduzidas com pintura em branco na cobertura de fibrocimento, estão na faixa de conforto térmico para frangos de corte na $1^{\circ}$ e $2^{\circ}$ semana de vida, indicando que para essa situação, apenas a pintura do telhado é suficiente para o acondicionamento térmico ambiental. Para animais, a partir da $3^{\circ}$ semana de vida, alternativas para acondicionamento térmico devem ser associadas a pintura do telhado, como por exemplo, ventiladores (pressão positiva) para aumentar a renovação do ar e favorecer a troca convectiva de calor do animal com o ambiente e, assim, promover uma melhoria no conforto térmico desses animais.

Para Costa et al. (2012), na concepção e dimensionamento de sistemas de climatização do aviário é necessário ter claro os objetivos e os meios disponíveis para alcançar os propósitos estabelecidos para a produção, para tal, torna-se prioritário o estudo do microclima do local onde serão implantadas as instalações. De acordo com Oliveira e Knies (2017), conhecer as condições climáticas de um local onde será implantado novas instalações ou em locais em que existe a necessidade de adaptação das instalações existentes para criação de aves de corte, é de extrema importância, sendo este, o principal subsídio técnico para que a adoção de mecanismos naturais e/ou artificiais de controle climático sejam eficientes. 


\section{Conclusões}

As avalições de temperatura e umidade relativa do ar no ambiente externo e no ambiente interno de galpões avícolas em escala reduzida permitiu verificar que as diferentes coberturas promoveram redução média do ITU de 84 para 76.

A utilização da pintura branca na cobertura de fibrocimento reduziu o ITU médio de 77,31 para 74,90 no interior dos modelos reduzidos de galpões avícolas

Baseado nas condições em que o estudo foi conduzido recomenda-se a pintura branca na cobertura de fibrocimento para a melhoria do conforto térmico no interior dos galpões avícolas.

\section{Agradecimentos}

Agradecimento ao programa FIPE Júnior/UFSM.

\section{Referências}

ABREU, P. G.; ABREU, V. M. N. Caracterização dos sistemas de aquecimento para aves. Concórdia: EmbrapaCNPSA, 2002. 10p. Artigo Técnico 21.

ABREU, V. M. N.; ABREU, P. G. Os desafios da ambiência sobre os sistemas de aves no Brasil. Revista Brasileira de Zootecnia, v.40, p.1-14, 2011 (supl. especial). Disponível em:< http://www.alice.cnptia.embrapa.br/bitstream/ doc/901939/1/osdesafiosdaambienciasobreossistemas.pdf $>$.

BORGES, S.A.; MAIORKA, A.; SILVA, A.V.F. Heat stress physiology and electrolytes for broilers. Ciência Rural, Santa Maria, v.33, n.5, p.975-981, 2003. < http://dx.doi.org/10.1590/S0103-84782003000500028>.

BUNFFINGTON, D. E.; COLLAZO-AROCHO, A.;CANTON, G. H. D.; THATCHER, W. W.; COLLIER ,R. J. Black globe-humidity comfort index for dairy cows. American Society of Agricultural Engineers, 19f.1977.

CAMERINI, N. L.; NASCIMENTO, J. W. B.; FOOK, M. V. L.; SOARES, E. A.; SILVA, F. A. S. Análise de variáveis ambientais em modelos reduzidos de instalações agropecuárias com forro de resíduo de EVA. Revista Eletrônica de Materiais e Processos, Campina Grande, v. 4.2, p. 40-47, 2009.

CARDOSO, A. L. O. Índices de conforto térmico em modelos reduzidos de galpões avícolas com diferentes materiais de cobertura. Faculdade de Agronomia e Medicina Veterinária de Brasília, Distrito Federal, 2014.

CASA, A. C.; RAVELO, A. C. Acessing temperature and humidity dairy cattle in Córdoba, Argentina. International Journal of Biometeorology, Berlin, v. 48, n. 1, p. 6-9, 2003

CASTRO, J. O; SANTOS, G. C; AGUIAR, E. F; SOUSA, F. A; ALMEIDA, A. K; CAMPOS, A. T. Avaliação do índice de temperatura e umidade para as diferentes fases de produção de aves de corte no município de Diamantina - MG. Anais... XIII Encontro Latino Americano de Iniciação Científica e IX Encontro Latino Americano de Pós-Graduação - Universidade do Vale do Paraíba, 2009.

COSTA, J. H. S.; SANTOS, L. F. D. DOS; DANTAS, R. T. Diagnóstico bioclimático para produção de aves. Revista Verde, Mossoró - RN, vol. 7, n. 4, p.45 - 49, out-dez, 2012. < http://www.gvaa.com.br/revista/index.php/RVADS/ article/view/1392>.

CURTO, F. P. F.; NÄ̈̈S, I. A.; PEREIRA, D. F.; SALGADO, D. D. Estimativa do padrão de preferência térmica de matrizes pesadas (frangos de corte). Revista Brasileira de Engenharia Agrícola e Ambiental, v.11, p.211-216, 2007. 
FERREIRA JÚNIOR, L. G.; YANAGI JUNIOR, T.; DAMASCENO, F.; SILVA, E.; SILVA, G. C. A. Ambiente térmico no interior de modelos físicos de galpões avícolas equipados com câmaras de ventilação natural e artificial. Engenharia na Agricultura, Viçosa, MG, v. 27, n. 3, p. 166-178, 2009.

FONSECA, P. C. F.; ALMEIDA, E. A.; PASSINI, R. Ambiente térmico no interior de abrigos individuais para bezerros com a utilização de diferentes tipos de coberturas. Engenharia Agrícola, v.31, p.1044- 1051, 2011.

INSTITUTO BRASILEIRO DE GEOGRAFIA E ESTATÍSTICA (IBGE). Censo agropecuário 2006. Rio de Janeiro, 2007.

INSTITUTO BRASILEIRO DE GEOGRAFIA E ESTATÍSTICA (IBGE). Cidades. Disponível em: http://www.cidades. ibge.gov.br/xtras/home.php. Acesso em: 07/07/2016.

MACHADO, N. S.; TINÔCO, I. F. F.; ZOLNIER, S.; MOGAMI, C. A.; DAMASCENO, F. A.; ZEVIANI, W. M. Resfriamento da cobertura de aviários e seus efeitos na mortalidade e nos índices de conforto térmico. Nucleus, v.9, n.2, 2012.

MOURA, D. J. Ambiência na avicultura de corte. In: SILVA, I. J. O. Ambiência na Produção de Aves em Clima Tropical. p.75-149. FUNEP - Piracicaba, 2001.

NÄÄS, I. A. Princípios de conforto térmico na produção animal. São Paulo: Ícone, p.183, 1989.

OLIVEIRA, Z.B; KNIES, A.E. Diagnóstico bioclimático para a produção de aves de corte em diferentes municípios do RS. Energia na agricultura, v.32, p.372-378, 2017.

SANTOS, P. A.; YAHAGI JUNIOR, T.; TEIXEIRA, V. H.; FERREIRA, L. Ambiente térmico no interior de modelos de galpões avícolas em escala reduzida com ventilação natural e artificial dos telhados. Engenharia Agrícola, Jaboticabal, v. 25, n. 3, p. 575-584, 2005.

SEVEGNANI, K.B.; GHELFI FILHO, H.; SILVA, I.J.O, Comparação de vários materiais de cobertura através de índices de conforto térmico. Scientia Agricola, Piracicaba-SP, v.51, n.1, pp. 1-7, 1994.

SILVA, E. T. Índice de temperatura e umidade (ITU) na produção de aves para a Mesoregião do Nordeste e Norte pioneiro Paranaence. Revista Acadêmica, V.5, n.4, p.385,390, 2007.

SILVA, K. C. P.; CAMPOS, A. T.; YANAGI JUNIOR, T.; CECCHIN, D.; LOURENÇONI, D.; FERREIRA, J. C. Reaproveitamento de resíduos de embalagens Tetra Pak-® em coberturas. Revista Brasileira de Engenharia Agrícola e Ambiental Campina Grande, PB, v.19, n.1, p.58-63, 2015. 